\title{
PENILAIAN KUALITAS APLIKASI HALAL MUI DENGAN WEBQUAL 4.0 DAN PENGARUHNYA TERHADAP KEPUTUSAN PENGGUNAAN
}

\author{
Ida Giyanti*), Erni Suparti \\ Program Studi Teknik Industri, Fakultas Teknik, Universitas Setia Budi \\ Jl. Letjend Sutoyo, Mojosongo, Jebres, Surakarta, 57127
}

(Received: August 15, 2017/ Accepted: May 31, 2018)

\begin{abstract}
Abstrak
Aplikasi Halal MUI adalah aplikasi berbasis Android yang diluncurkan oleh MUI untuk membantu konsumen mengecek status kehalalan produk melalui smartphone. Penelitian ini bertujuan mengukur kualitas aplikasi Halal MUI berdasarkan persepsi pengguna dan melihat pengaruh kualitas tersebut terhadap niat pengguna untuk menggunakan aplikasi Halal MUI. Pengukuran kualitas aplikasi Halal MUI dilakukan dengan menggunakan tiga variabel dalam Webqual 4.0. Uji hubungan antara variabel kualitas terhadap keputusan penggunaan dilakukan dengan analisis regresi linier berganda. Hasil penelitian menunjukkan bahwa rata-rata nilai kualitas adalah 3,08 dari skala 4,00 yang berarti bahwa aplikasi Halal MUI dinilai berkualitas baik oleh pengguna. Hasil uji keterandalan model dengan uji $F$ menunjukkan bahwa model regresi linier yang diestimasi layak digunakan untuk menjelaskan pengaruh kualitas aplikasi smartphone terhadap keputusan penggunaan. Hasil uji t pada ketiga variabel kualitas menunjukkan bahwa ketiga variabel Webqual 4.0 memiliki pengaruh yang signifikan terhadap niat pengguna untuk menggunakan aplikasi Halal MUI di kemudian hari. Variabel usability, information quality, dan service interaction mampu menjelaskan niat penggunaan aplikasi Halal MUI sebesar 43,7\%.
\end{abstract}

Kata kunci: Aplikasi smartphone; Halal MUI; Kualitas website; Regresi linier berganda; Webqual 4.0

\begin{abstract}
Halal MUI app is an Android-based application launched by Indonesian Ulemas Council (MUI) in order to help moslem customers to validate products' status through a smartphone. This research aims to evaluate the quality of Halal MUI application based on users' perception and then analyze the effect of these qualities to the intent to reuse the Halal MUI app. Quality of Halal MUI app is measured using three variables in Webqual 4.0. Multiple regression analysis is then employed to analyze the relationship between quality variables and users' intention to reuse the application. Result of quality measurement showed that the quality average score is 3,08 of 4,00 scale. It means that the quality of Halal MUI app is rated good by the users. Based on the F-test, it can be concluded that multiple regression model developed in this research is statistically significant and feasible to be used to explain the effects of smartphone application quality on users' desicion to reuse the application. Based on the t-test for all three quality variables, it can be summarized that all variables in Webqual 4.0 have a strong influence on users' intention to reuse the Halal MUI app in the future. Three variables of Webqual 4.0, namely usability, information quality, and service interaction, are able to explain $43,7 \%$ of overall users' intention to reuse Halal MUI app.
\end{abstract}

Keywords: Smartphone application; Halal MUI; Website quality; Multiple regression; Webqual 4.0

\section{Pendahuluan}

Perkembangan teknologi informasi dan komunikasi yang sangat pesat telah melahirkan beragam website dan

\footnotetext{
*) Penulis Korespondensi.

E-mail: idagiyanti@setiabudi.ac.id
}

aplikasi berbasis web yang dapat diunduh dan digunakan pada smartphone. Sampai dengan Juni 2017, aplikasi smartphone berbasis Android yang terdaftar di Google Play Store telah mencapai 3 juta (www.statista.com). Aplikasi berbasis Android berfungsi semacam website, dimana website bertindak sebagai jendela bagi pengguna untuk melakukan interaksi dengan organisasi penyedia 
layanan aplikasi (Zhang \& Von Dran, 2002). Dengan banyaknya website serta semakin kompleksnya kebutuhan pengguna terhadap layanan website yang ditawarkan, kualitas website menjadi salah satu hal utama yang menjadi perhatian agar website tersebut betul-betul dirasakan manfaatnya oleh pengguna (Elangovan, 2013).

Salah satu aplikasi yang terdaftar di Google Play Store ialah aplikasi Halal MUI. Aplikasi Halal MUI ialah aplikasi berbasis Android yang menyediakan layanan daring untuk membantu konsumen mengecek status kehalalan produk melalui smartphone. Aplikasi ini diluncurkan oleh MUI pada Februari 2016 untuk menjawab kekhawatiran konsumen muslim terhadap status kehalalan produk. Meskipun konsumen dapat melihat status kehalalan produk melalui logo halal di kemasan produk, namun konsumen masih sering ragu apakah logo yang tercantum tersebut asli atau tidak. Melalui aplikasi Halal MUI, konsumen dapat mengecek bukan saja informasi status kehalalan produk tetapi juga dapat melihat nomor sertifikat halal dan masa berlaku sertifikat halal.

Aplikasi Halal MUI sampai saat ini telah diunduh oleh 50 ribu pengguna. Jumlah tersebut tentu masih sedikit dibandingkan dengan populasi muslim di Indonesia yang menggunakan smartphone berbasis Android. Rendahnya tingkat penggunaan website oleh pengguna dipengaruhi secara signifikan oleh kualitas website (Loiacono et al., 2002). Sejauh pengetahuan penulis, penelitian mengenai kualitas aplikasi Halal MUI belum pernah dilakukan. Selama ini, pengguna hanya memberikan umpan balik terhadap kualitas aplikasi Halal MUI dengan memberikan komentar pada kolom komentar di Google Play Store. Untuk itu, perlu dilakukan penelitian untuk menilai kualitas aplikasi Halal MUI berdasarkan persepsi pengguna dan apakah kualitas aplikasi berpengaruh pada keinginan pengguna untuk menggunakan aplikasi tersebut.

Untuk mengevaluasi kualitas website, terdapat beberapa metode yang dapat digunakan yaitu EtailQ, Webqual 4.0, Sitequal, dan NetQual (Bressolles \& Nantel, 2008). Penelitian ini menggunakan metode Webqual 4.0 yang dikembangkan oleh Barnes \& Vidgen (2003). Hal ini didasari oleh alasan bahwa skala pengukuran dalam Webqual 4.0 telah tervalidasi untuk mengukur kualitas layanan website sehingga Webqual 4.0 menjadi satu metode yang paling banyak diterima dan diaplikasikan oleh beberapa peneliti (Barnes \& Vidgen, 2005). Webqual 4.0 merupakan ekstensi dari versi Webqual sebelumnya. Webqual 4.0 pada dasarnya digunakan untuk mengukur kualitas website komersial. Namun dalam perkembangannya, Webqual 4.0 juga telah digunakan untuk mengukur kualitas layanan pada berbagai jenis website sebagaimana dilakukan oleh Park et al. (2011), Medyawati \& Mabruri (2012), Elangovan
(2013), Hasanov \& Khalid (2015), Sastika (2016), dan Syaifullah \& Soemantri (2016).

Namun demikian, Webqual 4.0 belum pernah digunakan untuk mengukur kualitas aplikasi smartphone berbasis Android. Oleh karena itu, perlu dilakukan penelitian tentang penerapan Webqual 4.0 pada aplikasi smartphone berbasis Android untuk menilai apakah Webqual 4.0 valid digunakan untuk menilai kualitas pada layanan teknologi informasi dan komunikasi lainnya selain website. Penelitian Loiacono et al., (2002) telah membuktikan bahwa kualitas website berpengaruh secara positif terhadap keputusan pengguna untuk mengunjungi kembali website tersebut. Oleh karena itu, selain menilai kualitas aplikasi, penelitian ini ingin menguji apakah terdapat pengaruh antara kualitas aplikasi Halal MUI terhadap keinginan pengguna untuk menggunakan kembali aplikasi tersebut.

\section{Bahan dan Metode}

Model dasar yang digunakan sebagai acuan untuk melakukan penelitian adalah Webqual 4.0 dan regresi linier berganda. Webqual 4.0 digunakan untuk mengukur kualitas aplikasi Halal MUI berdasarkan persepsi pengguna. Webqual 4.0 terdiri atas tiga variabel yaitu usability, information quality, dan service interaction yang dijabarkan dalam 22 item pertanyaan. Variabel usability mengukur persepsi pengguna terhadap tingkat kemudahan penggunaan website, seperti kemudahan untuk dipelajari, kemudahan pencarian informasi, kemudahan navigasi, dan kemudahan dalam pengoperasian. Variabel information quality mengukur akurasi, keterbaruan, kelengkapan, dan kesesuaian informasi yang ditampilkan dalam website. Sedangkan variabel service interaction mengukur kualitas tampilan website. Dan untuk melihat pengaruh setiap variabel Webqual 4.0 terhadap keputusan penggunaan aplikasi Halal MUI digunakan analisis regresi linier berganda. Model penelitian yang dilakukan ditampilkan pada Gambar 1. Hipotesis pada penelitian ini ialah:

$\mathrm{H}_{1}$ : usability berpengaruh positif pada intention to use

$\mathrm{H}_{2}$ : information quality berpengaruh positif terhadap intention to use

$\mathrm{H}_{3}$ : service interaction berpengaruh positif terhadap intention to use

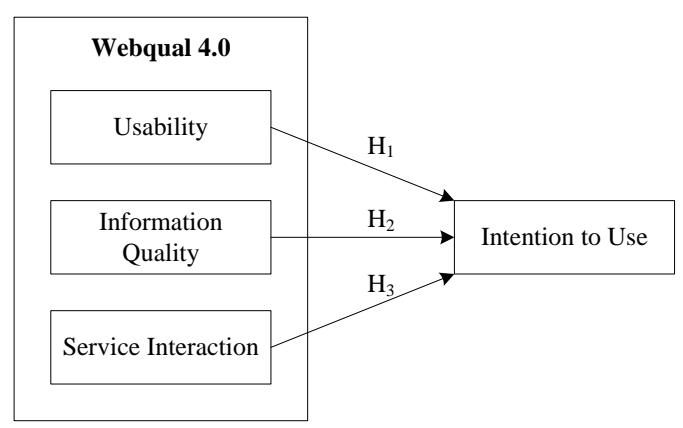

Gambar 1. Model penelitian 
Metode penelitian yang digunakan dalam penelitian ini ialah metode kuantitatif. Instrumen yang digunakan untuk melakukan pengumpulan data ialah dengan kuesioner. Kuesioner terdiri dari empat bagian, yaitu bagian pembuka, penjelasan tentang aplikasi Halal MUI, informasi personal responden, dan inti yang berisi pertanyaan terkait dengan kualitas aplikasi Halal MUI. Item pertanyaan pada bagian inti dinilai menggunakan skala Likert dari 1 sampai 4 dimana skala "1" menyatakan "sangat tidak setuju" dan skala"4" menyatakan "sangat setuju".

Instrumen pengukuran kualitas aplikasi Halal MUI disusun berdasarkan item pertanyaan pada Webqual 4.0. Karena obyek dalam penelitian ini ialah aplikasi berbasis Android, sedangkan Webqual 4.0 ditujukan untuk mengukur kualitas website, maka 22 item pertanyaan dalam Webqual 4.0 perlu dilakukan modifikasi. Modifikasi diperlukan agar item pertanyaan sesuai dengan kontek penelitian. Selain mengacu pada item pertanyaan yang terdapat di Webqual 4.0, modifikasi item pertanyaan juga mengacu pada penelitian yang dilakukan oleh Norman et al. (2009). Norman et al. (2009) meneliti kualitas aplikasi pengecekan status halal produk berbasis Radio Frequency Identification (RFID) serta menilai penerimaan konsumen terhadap aplikasi tersebut. Itemitem pertanyaan pada penelitian Norman et al. (2009) dinilai relevan untuk digunakan pada penelitian ini karena kesamaan obyek yang dikaji.

Webqual 4.0 hanya mencakup item pertanyaan tiga variabel kualitas website. Sedangkan pertanyaan variabel dependen (niat penggunaan aplikasi) belum diakomodir dalam Webqual 4.0. Dalam penelitian ini, item pertanyaan untuk variabel dependen (intention to use) dimodifikasi dari penelitian Rahman et al. (2016).

Setelah item pertanyaan kuesioner disusun, dilakukan pengumpulan data yang dibagi dalam dua tahap yaitu pengumpulan data awal dan pengumpulan data utama. Pengumpulan data awal dilakukan untuk uji validitas, uji reliabilitas, dan perbaikan susunan kalimat (wording) pada item pertanyaan. Pada pengumpulan data awal ini, responden selain melakukan simulasi pengisian kuesioner, juga memberikan umpan balik terhadap isi kuesioner untuk memastikan bahwa setiap item pertanyaan dipahami dengan baik oleh responden. Setelah itu, dilakukan revisi untuk kemudian kuesioner hasil revisi disebarkan kepada responden untuk mendapatkan data utama yang digunakan untuk menjawab pertanyaan penelitian.

Teknik pengambilan sampel yang digunakan untuk pengumpulan data ialah purposive sampling. Kriteria sampel yang dijadikan responden ialah konsumen muslim dewasa yang memiliki dan terbiasa menggunakan smartphone. Penyebaran kuesioner dilakukan di beberapa tempat seperti kampus, perumahan, dan pusat perbelanjaan di Solo Raya. Kemudian setelah data terkumpul, dilakukan pengolahan data untuk menjawab tujuan penelitian yang telah dirumuskan.

\section{Hasil dan Pembahasan}

\subsection{Variabel Penelitian dan Indikatornya}

Indikator atau item pertanyaan yang digunakan pada penelitian ini ditampilkan pada Tabel 1.

Tabel 1. Variabel Penelitian dan Indikatornya

\begin{tabular}{|c|c|c|}
\hline Variabel & Indikator & Sumber \\
\hline $\begin{array}{l}\text { Usability } \\
\text { (USE) }\end{array}$ & $\begin{array}{l}\text { 1. Secara umum, Halal MUI sangat bermanfaat bagi konsumen } \\
\text { 2. Halal MUI membantu mengecek keaslian logo halal yang tercantum di kemasan } \\
\text { 3. Halal MUI mengurangi keraguan saya tentang status halal produk } \\
\text { 4. Halal MUI mudah digunakan } \\
\text { 5. Halal MUI mudah untuk dipelajari } \\
\text { 6. Untuk menggunakan Halal MUI tidak memerlukan keahlian khusus }\end{array}$ & \multirow{3}{*}{$\begin{array}{l}\text { Barnes \& } \\
\text { Vidgen, } \\
(2003), \\
\text { Norman et al. } \\
(2009)\end{array}$} \\
\hline $\begin{array}{l}\text { Information } \\
\text { Quality } \\
\text { (INF) }\end{array}$ & $\begin{array}{l}\text { 1. Halal MUI memberikan informasi yang dipercaya tentang status kehalalan produk } \\
\text { 2. Halal MUI menyediakan informasi terkini tentang status halal suatu produk } \\
\text { 3. Informasi pada Halal MUI bersifat up to date } \\
\text { 4. Halal MUI memberikan informasi yang lengkap tentang status kehalalan produk }\end{array}$ & \\
\hline $\begin{array}{l}\text { Service } \\
\text { Interaction } \\
(\mathrm{SERV})\end{array}$ & $\begin{array}{l}\text { 1. Tampilan Halal MUI menarik } \\
\text { 2. Status kehalalan produk dapat dengan mudah dicek lewat Halal MUI } \\
\text { 3. Mengecek status halal lewat Halal MUI tidak memerlukan waktu yang lama }\end{array}$ & \\
\hline $\begin{array}{l}\text { Intention to } \\
\text { Use } \\
\text { (IU) }\end{array}$ & $\begin{array}{l}\text { 1. Saya akan menggunakan Halal MUI setiap saya berbelanja produk makanan } \\
\text { 2. Saya akan menggunakan Halal MUI untuk mendapatkan informasi status halal produk yang } \\
\text { saya beli } \\
\text { 3. Saya tetap akan menggunakan Halal MUI dalam jangka panjang } \\
\text { 4. Saya akan menggunakan Halal MUI saat saya merasa ragu-ragu mengenai status halal } \\
\text { produk yang saya beli } \\
\text { 5. Saya tetap akan mengecek status halal produk yang saya beli lewat Halal MUI meskipun di } \\
\text { kemasan produk sudah dicantumkan label halal }\end{array}$ & $\begin{array}{l}\text { Rahman et } \\
\text { al.(2016) }\end{array}$ \\
\hline
\end{tabular}




\subsection{Uji Validitas}

Pada penelitian ini digunakan uji validitas Product Moment Pearson Correlation. Jumlah sampel pada pengumpulan data awal ialah 30 . Untuk jumlah data $(\mathrm{N})$ $=30$ dengan taraf signifikansi 5\%, diketahui nilai $r_{\text {tabel }}=$ 0,361 . Nilai $r_{\text {tabel }}$ ini kemudian dibandingkan dengan $r_{\text {hitung }}$ yang diperoleh dari output SPSS 17.0. Tabel 2 menunjukkan bahwa semua nilai $r_{\text {hitung }}$ lebih besar daripada $r_{\text {tabel }}$ sehingga dapat disimpulkan bahwa seluruh item kuesioner valid.

Tabel 2. Hasil Pengujian Validitas

\begin{tabular}{cccc}
\hline Kode & $\boldsymbol{r}_{\text {hitung }}$ & $\boldsymbol{r}_{\text {tabel }}$ & Keterangan \\
\hline USE1 & 0,488 & 0,361 & Valid \\
\hline USE2 & 0,628 & 0,361 & Valid \\
\hline USE3 & 0,678 & 0,361 & Valid \\
\hline USE4 & 0,398 & 0,361 & Valid \\
\hline USE5 & 0,424 & 0,361 & Valid \\
\hline USE6 & 0,465 & 0,361 & Valid \\
\hline INF1 & 0,746 & 0,361 & Valid \\
\hline INF2 & 0,633 & 0,361 & Valid \\
\hline INF3 & 0,600 & 0,361 & Valid \\
\hline INF4 & 0,547 & 0,361 & Valid \\
\hline SERV1 & 0,651 & 0,361 & Valid \\
\hline SERV2 & 0,563 & 0,361 & Valid \\
\hline SERV3 & 0,531 & 0,361 & Valid \\
\hline IU1 & 0,747 & 0,361 & Valid \\
\hline IU2 & 0,648 & 0,361 & Valid \\
\hline IU3 & 0,747 & 0,361 & Valid \\
\hline IU4 & 0,629 & 0,361 & Valid \\
\hline IU5 & 0,711 & 0,361 & Valid \\
\hline
\end{tabular}

\subsection{Uji Reliabilitas}

Tingkat reliabilitas variabel dinilai dari nilai Alpha Cronbach. Hasil pengukuran reliabilitas sebagaimana pada Tabel 3 menunjukkan bahwa nilai Alpha Cronbach untuk seluruh variabel telah melebihi nilai 0,6 sehingga dapat disimpulkan bahwa konstruk yang disusun pada seluruh variabel telah reliabel.

Tabel 3. Hasil Pengujian Reliabilitas

\begin{tabular}{ccc}
\hline Variabel & Alpha Cronbach & Keterangan \\
\hline USE & 0,709 & Reliabel \\
\hline INF & 0,686 & Reliabel \\
\hline SERV & 0,720 & Reliabel \\
\hline IU & 0,752 & Reliabel \\
\hline
\end{tabular}

\subsection{Profil Responden}

Jumlah kuesioner yang terkumpul pada tahap pengumpulan data utama ialah 200 kuesioner. Setelah dilakukan penyaringan data melalui analisis missing value dan analisis outlier, 179 kuesioner dapat digunakan untuk pengolahan data selanjutnya. Profil responden ditampilkan pada Tabel 4.

\subsection{Kualitas Halal MUI}

Berdasarkan profil responden pada Tabel 4 diketahui bahwa sebagian besar responden $(84,36 \%)$ belum mengetahui adanya aplikasi Halal MUI. Oleh karena itu, untuk menilai kualitas Halal MUI, sebelum responden tersebut memberikan penilaian, responden yang bersangkutan diberikan penjelasan tentang aplikasi Halal MUI serta diberikan kesempatan untuk mencoba melacak status kehalalan beberapa produk melalui aplikasi Halal MUI. Setelah responden mengetahui fungsi dan telah mencoba sendiri kegunaan aplikasi Halal MUI, selanjutnya diminta mengisi kuesioner. Hasil penilaian kualitas aplikasi Halal MUI berdasarkan persepsi pengguna ditampilkan pada Tabel 5.

Tabel 4. Profil Responden

\begin{tabular}{|c|c|c|c|}
\hline \multicolumn{2}{|l|}{ Indikator } & Jumlah & Persentase \\
\hline \multirow{2}{*}{ Jenis Kelamin } & Laki-Laki & 95 & $53,07 \%$ \\
\hline & Perempuan & 84 & $46,93 \%$ \\
\hline \multirow{4}{*}{ Usia } & $<21$ tahun & 69 & $38,76 \%$ \\
\hline & 21-30 tahun & 61 & $34,27 \%$ \\
\hline & 31-40 tahun & 44 & $24,16 \%$ \\
\hline & 41-50 tahun & 5 & $2,81 \%$ \\
\hline \multirow{7}{*}{ Pendidikan } & SD & 2 & $1,12 \%$ \\
\hline & SMP & 13 & $7,26 \%$ \\
\hline & SMU/SMK & 96 & $53,63 \%$ \\
\hline & D3 & 18 & $10,06 \%$ \\
\hline & D4/S1 & 42 & $33,46 \%$ \\
\hline & S2 & 6 & $3,35 \%$ \\
\hline & S3 & 2 & $1,12 \%$ \\
\hline \multirow{2}{*}{ Pengetahuan Aplikasi Halal MUI } & Tahu & 28 & $15,64 \%$ \\
\hline & Belum Tahu & 151 & $84,36 \%$ \\
\hline \multirow{2}{*}{ Penggunaan Aplikasi Halal MUI } & Pernah & 10 & $5,59 \%$ \\
\hline & Belum Pernah & 169 & $94,41 \%$ \\
\hline
\end{tabular}


Tabel 5. Kualitas Halal MUI

\begin{tabular}{|c|c|c|c|}
\hline Kode & $\begin{array}{c}\text { Rata-Rata } \\
\text { Skor }\end{array}$ & $\begin{array}{c}\text { Standar } \\
\text { Deviasi }\end{array}$ & $\begin{array}{c}\text { Rata-Rata } \\
\text { Skor Variabel }\end{array}$ \\
\hline USE1 & 3,32 & 0,57 & 3,16 \\
\hline USE2 & 3,14 & 0,49 & \\
\hline USE3 & 3,12 & 0,56 & \\
\hline USE4 & 3,16 & 0,53 & \\
\hline USE5 & 3,10 & 0,48 & \\
\hline USE6 & 3,11 & 0,51 & \\
\hline INF1 & 3,20 & 0,45 & 3,08 \\
\hline INF2 & 3,04 & 0,45 & \\
\hline INF3 & 3,03 & 0,50 & \\
\hline INF4 & 3,03 & 0,44 & \\
\hline SERV1 & 3,02 & 0,56 & 3,04 \\
\hline SERV2 & 3,07 & 0,46 & \\
\hline SERV3 & 3,02 & 0,54 & \\
\hline
\end{tabular}

Berdasarkan Tabel 5, diperoleh skor rata-rata kualitas aplikasi Halal MUI yang merupakan rata-rata skor ketiga variabel yaitu 3,08. Hal tersebut mengindikasikan bahwa menurut persepsi pengguna, aplikasi Halal MUI telah memiliki kualitas yang baik dilihat dari aspek usability, information quality, dan service interaction.

\subsection{Regresi Linier Berganda}

Sebelum membentuk model regresi linier berganda, terlebih dahulu dilakukan uji asumsi yang meliputi uji normalitas, multikolinearitas, autokorelasi, dan heteroskedastisitas. Model regresi linier yang baik ialah yang datanya berdistribusi normal serta terbebas dari terjadinya multikolinearitas, autokorelasi, maupun heteroskedastisitas. Hasil uji asumsi regresi linier berganda ditampilkan pada Tabel 6. Hasil pengujian asumsi memperlihatkan bahwa semua asumsi model regresi linier berganda dapat dipenuhi sehingga model regresi linier berganda dapat digunakan untuk menguji hipotesis penelitian. Hasil analisis regresi linier berganda ditampilkan pada Tabel 7, 8, dan 9.

Pada Tabel 7 diketahui bahwa model regresi linier berganda memiliki koefisien determinasi $\left(\mathrm{R}^{2}\right)$ sebesar 0,437 atau $43,7 \%$. Koefisien determinasi ialah koefisien yang menjelaskan proporsi pengaruh variabel independen terhadap variabel dependennya. Hal ini berarti bahwa variabel usability (USE), information quality (INF), dan service interaction (SERV) mampu menjelaskan niat penggunaan aplikasi Halal MUI sebesar $43,7 \%$. Sedangkan sisanya sebesar $56,3 \%$ dijelaskan oleh variabel lain yang belum tercakup dalam model regresi.

ANOVA dengan uji $\mathrm{F}$ sebagaimana ditampilkan pada Tabel 8 memperlihatkan bahwa nilai F sebesar 45,
301 dengan nilai signifikansi 0,000 . Nilai signifikansi ini lebih kecil daripada nilai $\alpha=0,05$, sehingga dapat disimpulkan bahwa model regresi yang diestimasi layak digunakan untuk menjelaskan pengaruh variabel independen terhadap variabel dependen.

Koefisien regresi paad Tabel 9 menjelaskan bagaimana variabel kualitas aplikasi Halal MUI mempengaruhi niat pengguna untuk menggunakan kembali aplikasi tersebut. Tabel 9 memperlihatkan bahwa ketiga variabel kualitas aplikasi (usability, information quality, dan service interaction) memiliki nilai signifikansi kurang dari nilai $\alpha=0,05$. Hal ini berarti bahwa variabel usability, information quality, dan service interaction berpengaruh secara signifikan terhadap niat penggunaan aplikasi Halal MUI.

Nilai $\mathrm{t}$ variabel service interaction sebesar 4,031 merupakan nilai $t$ terbesar dibanding nilai t dua variabel lainnya. Hal tersebut mengindikasikan bahwa variabel service interaction memiliki pengaruh yang paling kuat dalam menjelaskan variabel niat penggunaan aplikasi Halal MUI. Demikian juga nilai t variabel usability $(\mathrm{t}=3,162)$ lebih besar daripada nilai $\mathrm{t}$ variabel information quality $(\mathrm{t}=2,551)$. Hal ini berarti bahwa meskipun variabel information quality merupakan variabel yang penting dalam suatu aplikasi berbasis Android, namun pengaruh variabel information quality terhadap niat penggunaan aplikasi Halal MUI lebih lemah dibandingkan variabel usability. Berdasarkan Tabel 9 juga dapat dibentuk persamaan model regresi linier berganda, yaitu: $\mathrm{Y}=1,039+0,270 \mathrm{X}_{1}+0,317$ $\mathrm{X}_{2}+0,560 \mathrm{X}_{3}$ dimana $\mathrm{Y}=\mathrm{IU}, \mathrm{X}_{1}=\mathrm{USE}, \mathrm{X}_{2}=\mathrm{INF}$, dan $\mathrm{X}_{3}=$ SERV. Hasil ini menunjukkan bahwa semua hipotesis pada penelitian ini dapat terbukti yaitu variabel usability, information quality, dan service interaction berpengaruh secara positif terhadap intention to use. 
Tabel 6. Uji Asumsi Regresi Linier Berganda

\begin{tabular}{|c|c|c|c|c|}
\hline Jenis Pengujian & Metode & Hasil Uji & Kriteria & Keterangan \\
\hline Normalitas & $\begin{array}{l}\text { One-Sample } \\
\text { Kolmogorov Smirnov }\end{array}$ & $\begin{array}{l}\text { Signifikansi } \\
0,082\end{array}$ & $\begin{array}{l}\text { Jika nilai signifikansi }>0,05 \\
\text { maka data berdistribusi normal }\end{array}$ & $\begin{array}{l}\text { Data berdistribusi } \\
\text { normal }\end{array}$ \\
\hline Multikolinearitas & Tolerance dan VIF & $\begin{array}{l}\text { Tolerance: } \\
\text { USE: } 0,533 \\
\text { INF: } 0,568 \\
\text { SERV: } 0,494 \\
\text { VIF: } \\
\text { USE: } 1,878 \\
\text { INF: } 1,761 \\
\text { SERV: } 2,023\end{array}$ & $\begin{array}{l}\text { - Jika nilai Tolerance }>0,10 \\
\text { maka tidak terdapat } \\
\text { multikolinearitas } \\
\text { - Jika nilai VIF < } 10 \text { maka } \\
\text { tidak terdapat } \\
\text { multikolinearitas }\end{array}$ & $\begin{array}{l}\text { Tidak terjadi } \\
\text { multikolinearitas }\end{array}$ \\
\hline Autokorelasi & Durbin-Watson & DW: 1,861 & $\begin{array}{l}\text { Jika } 1,7896<\text { DW }<2,2104 \\
\text { maka tidak ada autokorelasi }\end{array}$ & $\begin{array}{l}\text { Tidak terjadi } \\
\text { autokorelasi }\end{array}$ \\
\hline Heteroskedastisitas & Rank Spearman & $\begin{array}{l}\text { Signifikansi: } \\
\text { USE: } 0,468 \\
\text { INF: } 0,789 \\
\text { SERV: } 0,476 \\
\end{array}$ & $\begin{array}{l}\text { Jika nilai signifikansi }>0,05 \\
\text { maka tidak terdapat gejala } \\
\text { heteroskedastisitas }\end{array}$ & $\begin{array}{l}\text { Tidak terjadi } \\
\text { heteroskedastisitas }\end{array}$ \\
\hline
\end{tabular}

Tabel 7. Ringkasan Model Regresi

\begin{tabular}{cccc}
\hline $\mathbf{R}$ & $\mathbf{R}^{\mathbf{2}}$ & Adj R $^{\mathbf{2}}$ & Std. Error \\
\hline 0,661 & 0,437 & 0,427 & 1,66322 \\
\hline
\end{tabular}

Tabel 8. ANOVA

\begin{tabular}{lccccc}
\hline \multicolumn{1}{c}{ Model } & Sum of Squares & df & Mean Square & F & Sig. \\
\hline Regression & 375,945 & 3 & 125,315 & 45,301 & 0,000 \\
Residual & 484,100 & 175 & 2,766 & & \\
Total & 860,045 & 178 & & & \\
\hline
\end{tabular}

Tabel 9. Koefisien Regresi

\begin{tabular}{lccccc}
\hline Model & $\boldsymbol{\beta}$ & Std. Error & Beta & t & Sig. \\
\hline Constant & 1,039 & 1,319 & & 0,788 & 0,432 \\
USE & 0,270 & 0,085 & 0,246 & 3,162 & 0,002 \\
INF & 0,317 & 0,124 & 0,192 & 2,551 & 0,012 \\
SERV & 0,560 & 0,139 & 0,325 & 4,031 & 0,000 \\
\hline
\end{tabular}

\subsection{Pembahasan}

Webqual 4.0 yang digunakan dalam penelitian ini sebenarnya merupakan kerangka untuk mengukur kualitas website. Dalam penelitian ini, Webqual 4.0 diadopsi dan kemudian disesuaikan untuk digunakan sebagai kerangka untuk mengukur faktor kualitas aplikasi berbasis Android. Hasil penelitian menunjukkan bahwa Webqual 4.0 masih cukup valid dan reliabel untuk mengukur kualitas layanan teknologi informasi dan komunikasi selain website. Hal ini dikarenakan adanya persamaan karakteristik antara website dan aplikasi mobile berbasis Android, yaitu sebagai jendela penghubung antara pengguna dengan organisasi. Namun demikian, berdasarkan Tabel 2 dan Tabel 3 diketahui bahwa nilai validitas dan reliabilitas alat ukur berbasis Webqual 4.0 berada sedikit di atas kriteria penerimaan.

Hasil regresi linier berganda menunjukkan bahwa pengguna berniat menggunakan aplikasi Halal MUI karena didorong oleh faktor kualitas aplikasi. Hasil penelitian ini semakin memperkuat hasil penelitian sebelumnya yang dilakukan oleh Loiacono et al., (2002) dan Sastika (2016). Loiacono et al., (2002) menyatakan bahwa keputusan pengguna untuk mengunjungi suatu website dipengaruhi oleh kualitas website tersebut. Sedangkan Sastika (2016) menyimpulkan bahwa terdapat pengaruh yang signifikan antara kualitas website terhadap keputusan pembelian pada website $e$ commerce Traveloka.

Namun demikian, meskipun menurut persepsi pengguna, aplikasi Halal MUI dinilai telah memiliki kualitas yang baik, aplikasi Halal MUI ini belum banyak diketahui dan digunakan oleh pengguna. Berdasarkan profil responden pada Tabel 4, diketahui bahwa dari 179 responden, hanya 28 orang $(15,64 \%)$ yang menyatakan telah mengetahui adanya aplikasi Halal MUI. Dan dari 28 orang tersebut, hanya 10 orang yang menyatakan pernah menggunakan dan merasakan manfaat aplikasi Halal MUI. Dan setelah responden diberikan sosialisasi 
singkat tentang aplikasi Halal MUI dan diminta mengeksplorasi fitur-fitur di dalam aplikasi, responden menilai bahwa aplikasi Halal MUI memiliki manfaat selain untuk mengecek status kehalalan produk juga mampu mengurangi keraguan terhadap keaslian logo halal yang tercantum pada kemasan produk.

Norman et al., (2009) juga berkesimpulan bahwa aplikasi pengecekan status kehalalan produk berbasis RFID di Malaysia dinilai pengguna sangat bermanfaat dan mampu mendukung Malaysia sebagai negara pusat halal. Indonesia, meskipun bukan merupakan negara Islam dan secara geografis berjarak ribuan kilometer dari negara tempat lahirnya agama Islam, namun Indonesia merupakan negara dengan populasi muslim terbesar di dunia. Bertolak pada kenyataan tersebut, seharusnya Indonesia menaruh perhatian yang lebih besar terhadap status halal produk dalam rangka memberikan jaminan keamanan terhadap konsumen muslim. Aplikasi Halal MUI merupakan salah satu bentuk perhatian pemerintah bagi konsumen muslim dengan menyediakan teknologi pengecekan status halal produk. Perancangan aplikasi ini tentunya memerlukan investasi yang tidak sedikit. Karena itu perlu didorong agar aplikasi Halal MUI ini dapat dimanfaatkan secara maksimal agar investasi pemerintah menjadi tidak siasia. Hal ini sejalan dengan hasil analisis regresi linier berganda yang menyatakan bahwa variabel kualitas aplikasi Halal MUI baru mampu menjelaskan variabel niat penggunaan aplikasi sebesar $43,7 \%$. Hal ini berarti masih terdapat variabel lain sebesar $56,3 \%$ yang belum terakomodasi dalam model penelitian ini. Variabel lain tersebut salah satunya adalah sosialisasi mengenai keberadaan dan manfaat aplikasi Halal MUI. Responden dalam penelitian ini menyatakan selama ini belum ada sosialisasi terkait aplikasi Halal MUI. Padahal melalui sosialisasi, dapat disampaikan informasi mengenai aplikasi Halal MUI kepada pengguna sehingga pengguna memahami manfaat dan cara penggunaan aplikasi yang pada akhirnya akan menguatkan niat pengguna untuk menggunakan aplikasi tersebut.

\section{Kesimpulan}

Berdasarkan hasil pengukuran kualitas aplikasi Halal MUI diketahui bahwa dari skala maksimal 4,00, pengguna memberikan skor 3,08 yang berarti bahwa menurut persepsi pengguna aplikasi Halal MUI memiliki kualitas yang baik. Pengukuran kualitas aplikasi Halal MUI dilakukan dengan mengacu pada Webqual 4.0 yang sejatinya digunakan untuk mengukur kualitas website. Meskipun Webqual 4.0 masih cukup valid dan reliabel untuk digunakan sebagai dasar pengukuran kualitas aplikasi mobile berbasis Android, namun akan lebih tepat jika dimensi kualitas pada Webqual 4.0 disesuaikan dengan obyek yang dikaji. Penelitian yang akan datang dapat mencoba mengembangkan dimensi kualitas termasuk indikator kualitas yang sesuai untuk obyek kajian aplikasi berbasis Android sehingga instrumen penelitian menjadi lebih valid dan reliabel.

Persepsi kualitas yang terdiri dari tiga variabel yaitu usability, information quality, dan service interaction terbukti memiliki pengaruh secara positif dan signifikan terhadap variabel niat pengguna untuk menggunakan kembali aplikasi Halal MUI. Namun demikian, tiga variabel kualitas tersebut baru mampu menjelaskan variabel niat penggunaan aplikasi sebesar $43,7 \%$. Sisanya sebesar $56,3 \%$ dijelaskan oleh variabel lain yang belum dicakup dalam model regresi linier berganda. Karena itu, penelitian selanjutnya dapat mengeksplorasi variabel independen lain untuk dimasukkan ke dalam model regresi sehingga dapat meningkatkan proporsi pengaruh variabel independen terhadap variabel dependen. Salah satu variabel independen yang dapat dimasukkan ke dalam model regresi ialah variabel sosialisasi.

\section{Ucapan Terima Kasih}

Penulis mengucapkan terima kasih kepada Universitas Setia Budi Surakarta yang telah memberikan dukungan finansial untuk penelitian ini.

\section{Daftar Pustaka}

Barnes, S., \& Vidgen, R. (2005). Data Triangulation in Action: Using Comment Analysis to Refine Web Quality Metrics. Proceedings of the 13th European Conference on Information Systems. Regensburg, Germany.

Barnes, S., \& Vidgen, R. (2003). Measuring Website Quality Improvements: A Case Study of the Forum on Strategic Management Knowledge Exchange. Industrial Management \& Data System , 103 (5), 297-30.

Bressolles, G., \& Nantel, J. (2008). The Measurement of Electronic Service Quality: Improvements and Application. International Journal of E-Business Research , 4 (3), 1-19.

Elangovan, N. (2013). Evaluating Perceived Quality of B-School Websites. IOSR Journal of Business and Management , 12 (1), 92-102.

Hasanov, J., \& H, K. (2015). The Impact of Website Quality on Online Purchase Intention of Organic Food in Malaysia: A WebQual Model Approach. Procedia Computer Science, 72, 382-389.

Loiacono, E., Chen, D., \& Goodhue, D. (2002). Webqual TM Revisited: Predicting the Intent to Reuse a Website. AMCIS 2002 Proceedings , 301309.

Medyawati, H., \& Mabruri, A. (2012). Website Quality: Case Study on Local Government Bank and State Own Bank in Bekasi City. Procedia Social and Behavioral Sciences , 65, 1086-1091. 
Norman, A., Md. Nasir, M., Mohd Fauzi, S., \& Azmi, M. (2009). Consumer Acceptance of RFID-Enabled Services in Validating Halal Status. Proceeding of the 9th International Symposium on Communications and Information Technology, 911-915.

Park, H., Son, S., \& Kim, H. (2011). Public Internet Service and Customer Satisfaction with a Focus on Public Agencies in Korea. Journal of the Korean Society for Quality Management, 39 (4), 565-572.

Rahman, A., Hanafiah, M., Abdul, M., \& Ruslee, A. (2016). Assessing Consumers' Willingness to Use Tagging Technology in Tracing Halal Status. International Journal Islamic Marketing and Branding , 1 (3), 272-284.
Sastika, W. (2016). Analisis Pengaruh Kualitas Website (Webqual 4.0) terhadap Keputusan Pembelian pada Website E-Commerce Traveloka (Studi Kasus: Pengguna Traveloka di Kota Bandung Tahun 2015). Seminar Nasional Teknologi Informasi dan Komunikasi 2016 (SENTIKA) (hal. 649-657). Yogyakarta: Universitas Atma Jaya.

Syaifullah, \& Soemantri, D. (2016). Pengukuran Kualitas Website Menggunakan Metode Webqual 4.0 (Studi Kasus: CV. Zamrud Multimedia Network). Jurnal Rekayasa dan Manajemen Sistem Informasi , 2 (1), 19-25.

Zhang, P., \& Von Dran, G. (2002). User Expecations and Rankings of Quality Factors in Different Website. Proceedings of International Journal of Electronic Commerce , 6 (2), 9-33. 